\title{
O Processo de Construção e a Experiência da Parentalidade em Casais Homossexuais
}

\author{
Marina Ortolan Araldi ${ }^{1, *}$ (D) \& Fernanda Barcellos Serralta ${ }^{2}$ (D) \\ ${ }^{1}$ Universidade La Salle, Canoas, RS, Brasil \\ ${ }^{2}$ Universidade do Vale do Rio dos Sinos, São Leopoldo, RS, Brasil
}

\begin{abstract}
RESUMO - Este estudo visa compreender o processo de construção e a experiência da parentalidade em quatro casais homossexuais. Foram entrevistados três casais de homens e um casal de mulheres, com idades entre 30 e 50 anos, que tinham filhos nessa relação. Os dados foram examinados por meio de uma análise qualitativa consensual (CQR), que gerou 29 categorias, resultando em quatro domínios: identidade sexual, vínculo conjugal, processo da parentalidade e exercício da parentalidade. Os resultados sugerem que a parentalidade é exercida com satisfação e responsabilidade; é um meio de inserir o casal na sociedade; é facilitada pelo apoio e complicada pelo preconceito social; caracteriza-se pela flexibilidade nos papéis parentais e prioriza a transmissão de valores de liberdade e respeito às diferenças.
\end{abstract}

PALAVRAS-CHAVE: parentalidade, homossexualidade, homoparentalidade, família, relações familiares

\section{The Structuring Process and the Experience of Parenthood in Same-Sex Couples}

\begin{abstract}
This study aims to understand the process of constitution and experience of parenthood in four same-sex couples. We interviewed three gay couples and a lesbian couple, aged between 30 and 50 years who had children in this relationship. We analyzed the data by Consensual Qualitative Research (CQR) and generated 29 categories, grouped into four domains: sexual identity, marital bond, parenting process and parenting experience. Overall results suggest that parenting is experienced with satisfaction and responsibility; is a way of inclusion in society; is facilitated by social support and complicated by social prejudice; is characterized by flexibility in parental roles; gives priority the transmission of values of freedom and respect for differences.
\end{abstract}

KEYWORDS: parenthood, homosexuality, homosexual parents, family, family relations

Enquanto a família constituída por casais do mesmo sexo ganha cada vez mais respaldo jurídico e científico ao redor do mundo, uma parcela da sociedade impactada pela diferença, ou pela ausência dela, considera que gays e lésbicas são incapazes de serem pais e mães. Embora isso ainda seja sugerido, desde a década de 80 organizações que estudam e regulamentam a saúde e os transtornos mentais - sendo elas American Psychiatric Association em 1980, o Conselho Federal de Psicologia em 1985 e a Organização Mundial de Saúde em 1990 - deixaram de tratar as distintas expressões de sexualidade como patologia, passaram a defender a inexistência de prejuízo no desenvolvimento dos filhos e, assim, abriram espaço para o reconhecimento da união de casais do mesmo sexo pelo Supremo Tribunal Federal em 2011, o que facilita a constituição de família por estes.

Apesar disso, atualmente tramitam diversos projetos de lei na Câmara dos Deputados que visam retroceder esses avanços, definindo família como "núcleo social formado a partir da união entre um homem e uma mulher", proibindo a adoção por homossexuais, não reconhecendo o casamento entre pessoas do mesmo sexo e questionando iniciativas que fujam ao heteronormativo. Diante de tais percepções, surge a necessidade de investigar como ocorre a parentalidade e os desafios que casais homossexuais enfrentam para constituir uma família.

Pesquisas norte-americanas apontam que o desejo da parentalidade existe em casais homossexuais masculinos

*E-mail: marinaaraldi@hotmail.com

- Submetido: 24/08/2015; Revisado: 14/10/2017; Aceito: 16/02/2018 
e femininos (D'Augelli, Rendina, \& Sinclair, 2007; Gates, Badgett, Macomber, \& Chambers, 2007; Goldberg, Downing, \& Moyer, 2012). Riskind e Patterson (2010) investigaram desejos, intenções e atitudes de parentalidade em gays e lésbicas, pareados a heterossexuais quanto ao gênero, idade, etnia e nível de escolaridade. Embora casais homossexuais tenham apresentado menor desejo de parentalidade do que casais heterossexuais, esse número também foi proeminente, contrariando o estereótipo de que gays e lésbicas não desejam ter filhos. Por outro lado, um estudo desenvolvido em Israel com gays sem filhos revela o quão difícil eles imaginam que seja vivenciar uma relação conjugal e parental (Shenkman, 2012). Do total de entrevistados, $68,2 \%$ tinham o desejo de serem pais, mas apenas $31 \%$ acreditavam ter grandes chances de concretizá-lo. Dos homens que não mantinham relacionamento estável, $91 \%$ desejavam formar um casal, mas apenas $43,2 \%$ acreditavam tornar isso possível.

No exercício da parentalidade, pesquisas sugerem que exista uma boa relação entre pais/mães homossexuais e seus filhos, identificando que esses casais dividem melhor o cuidado com a criança do que casais heterossexuais (Goldberg, 2010). A pesquisa de Miscioscia, Blavier, Pagone e Simonelli (2017) revela alta correlação entre ajuste conjugal e desempenho parental e sinaliza, também, que não foram encontradas diferenças na aliança parental de casais homossexuais e heterossexuais italianos e belgas. Em outra pesquisa (Golombok et al., 2014), revela-se que casais gays britânicos que adotaram crianças apresentam maior bem-estar na relação com o filho do que casais heterossexuais na mesma condição. Rodriguez e Paiva (2009) relataram um estudo com dois casais homossexuais que tinham filhos de relacionamentos heterossexuais anteriores e observaram que existe maior flexibilidade de papéis parentais, sendo que ambos os cônjuges alternavam atividades culturalmente associadas aos gêneros masculino e feminino. Meletti e Scorsolini-Comin (2015) revelaram o desejo da parentalidade em casais de gays e lésbicas e a percepção de que a família será lugar de cuidado, proteção e incentivo, tal qual em outras estruturas.

No Brasil, um levantamento bibliográfico sobre a parentalidade em casais do mesmo sexo revela a escassez de pesquisas empíricas na área da psicologia, o que pode, de alguma maneira, contribuir para que não sejam desmistificados os preconceitos existentes na sociedade sobre essa parentalidade. De modo geral, os estudos brasileiros indicam que a difícil tarefa de tornar-se pai ou mãe pode ser complicada pelo preconceito social e entraves jurídicos-legais. Uma pesquisa desenvolvida com estudantes concluintes dos cursos de psicologia, direito e serviço social, que em sua trajetória profissional irão se deparar com famílias nessas condições, aponta que crenças religiosas, moralistas e psicológicas levam à oposição ao casamento e à adoção entre homossexuais (Pereira, Torres, Falcão, \& Pereira, 2013).

$\mathrm{O}$ preconceito e a ausência de uma rede de apoio parecem contribuir para uma maior angústia no exercício da parentalidade nesse contexto. Corrêa (2012) investigou as concepções sobre a parentalidade em lésbicas que tiveram ou estavam planejando ter filhos e concluiu que assumir a homossexualidade e a maternidade em uma sociedade heteronormativa incita a luta pelos direitos humanos e de cidadania dessas mulheres.

Embora gays e lésbicas manifestem desejo pela parentalidade, a sua concretização parece ser dificultada por condições biológicas (a infertilidade como casal), psicológicas (assumir a homossexualidade), sociais (preconceito e ausência de apoio social), entre outras. Há, entretanto, poucos estudos sobre as especificidades da parentalidade nesses casais no Brasil. Sendo assim, esta pesquisa visa compreender o processo de construção e a experiência da parentalidade em casais homossexuais, visando ampliar o conhecimento científico e contribuir para a diminuição de preconceitos e estereótipos sobre o tema.

\section{MÉTODO}

\section{Participantes}

Quatro casais, com idades entre 30 anos e 50 anos, sendo três casais de homens que adotaram seus filhos e um casal de mulheres que engravidou através da fertilização in vitro (FIV). A Tabela 1 apresenta a identificação dos entrevistados caracterizando nome, faixa etária, tempo de relação, filiação e método utilizado para alcançar a parentalidade.

Tabela 1

Identificação dos Entrevistados

\begin{tabular}{lcccc}
\hline Nome & Faixa etária & Tempo de relação & Filiação & Método \\
\hline $\begin{array}{l}\text { Alex e André } \\
\text { Casal A }\end{array}$ & 35 a 40 anos & 16 anos & Um menino de 4 anos & Adoção \\
$\begin{array}{l}\text { Bruno e Bernardo } \\
\text { Casal B }\end{array}$ & 45 a 50 anos & 19 anos & Dois meninos de 14 e 8 anos & Adoção \\
$\begin{array}{l}\text { Carlos e César } \\
\text { Casal C }\end{array}$ & 35 a 45 anos & 11 anos & Dois meninos de 9 e 4 anos e uma menina & de 6 anos \\
$\begin{array}{l}\text { Daniela e Denise } \\
\text { Casal D }\end{array}$ & 30 a 45 anos & 8 anos & Um menino e uma menina de 6 meses & Fertilização in vitro \\
\hline
\end{tabular}


Uma das mulheres foi casada com um homem durante dez anos e um dos homens teve um relacionamento de sete anos com uma mulher e de três anos com outro homem. Os demais participantes apenas tiveram relacionamentos estáveis com os atuais parceiros, cuja duração variava de 8 a 19 anos.

Os casais tiveram filhos com idades e características variadas. $\mathrm{O}$ casal $\mathrm{A}$ adotou um menino aos três meses, que hoje está com quatro anos; o casal B adotou dois irmãos há quatro anos, que hoje têm 8 e 14 anos; o casal $\mathrm{C}$ adotou há 2 anos e seis meses três irmãos, sendo dois meninos de 9 e 4 anos e uma menina de 6 anos e o casal D gerou gêmeos, um menino e uma menina de seis meses. $\mathrm{O}$ tempo de espera para entrada na fila de adoção ou para início do processo de FIV variou de 10 meses a 3 anos e 6 meses. A exceção foi o casal C, que, ao invés de entrar na fila de adoção, conheceu os filhos em uma creche. Nesse caso, as crianças, que estavam para adoção, passavam o dia na creche, dormiam no abrigo e nos finais de semana ficavam na casa da família biológica. Os progenitores ainda tinham a guarda dos filhos e, para que a adoção fosse concretizada, foi necessário entrar com um pedido de destituição do poder familiar.

Em todos os casos de adoção, o tempo entre o momento em que os pais conheceram as crianças e efetivaram a adoção foi de até 4 meses. No casal D, Denise foi a primeira a passar pelo processo de FIV, com duas tentativas frustradas ao longo de dois anos. Após esse período, Daniela iniciou o processo e, em 4 meses, estava grávida dos gêmeos. Todos os filhos adotivos são negros e os filhos biológicos são brancos.

Os participantes desta pesquisa foram selecionados por conveniência e se caracterizavam por serem brancos ou pardos, residirem na região metropolitana de Porto Alegre, terem ao menos ensino médio completo e apresentarem uma relação estável com os filhos. Com o objetivo de analisar o processo de parentalidade vivido pelo casal, não foram entrevistados pais e mães com filhos de outros relacionamentos.

\section{Instrumento}

Foi realizada uma entrevista semiestruturada com cada casal para compreender a constituição e expressão da identidade sexual, a formação do vínculo conjugal, o projeto e a concretização da parentalidade, a chegada do filho e as vivências da parentalidade. Esses tópicos foram definidos a partir do objetivo deste artigo e aplicados em uma entrevista piloto para verificação do roteiro e treinamento do método de análise de dados. Todas as entrevistas foram realizadas pela primeira autora deste artigo, psicóloga e pós-graduada em infância e família, e tiveram duração de uma hora e trinta minutos a três horas e trinta minutos.

\section{Procedimentos}

O contato com os participantes foi por telefone e as entrevistas foram agendadas na casa dos casais no período de abril a julho de 2014. Os participantes consentiram que a entrevista fosse gravada em áudio, transcrita e encaminhada a eles por e-mail com a finalidade de verificar o conteúdo e realizar correções ou adições aos dados coletados. Nenhum dos casais apresentou modificações sobre seu relato. Com o intuito de preservar suas identidades, todos os nomes foram alterados. Após a entrevista, foi solicitado que os participantes indicassem outros casais, método conhecido como snowball (bola de neve). O estudo foi aprovado pelo Comitê de Ética da instituição de origem das autoras (Resolução n. 176/2013) e foram respeitados todos os critérios de pesquisa com seres humanos presentes na Resolução n. 196/96 do Conselho Nacional de Saúde.

\section{Análises de Dados}

Os dados foram avaliados através da Consensual Qualitative Research (CQR), um método de análise qualitativa consensual que estuda, com profundidade, as experiências internas do sujeito, procurando minimizar o viés do pesquisador. $\mathrm{O} C \mathrm{CQ}$ tem, em seus componentes básicos, o uso de questões abertas para coleta de dados, utilização de múltiplos pontos de vista (juízes), decisões por consenso, auditor para checar o consenso, valorização da palavra, das narrativas e histórias, importância do contexto, uso de amostras pequenas, cuidado ético, atenção à cultura e retorno contínuo aos dados brutos para verificar a veracidade dos entendimentos (Hill , 2012).

A análise dos dados foi realizada pelas autoras deste artigo e dois graduandos em psicologia, um do sexo feminino e outro do sexo masculino. A primeira etapa de análise dos dados foi definir os domínios, estabelecendo termos gerais que englobavam os principais aspectos a serem avaliados na entrevista. Na segunda etapa, foram destacadas na entrevista as ideias centrais de cada fala, com o intuito de preencher os domínios. Para isso, a primeira autora e um graduando realizaram individualmente a codificação de cada entrevista, entraram em consenso sobre cada ideia central e o enviaram para a auditora, segunda autora do artigo. A auditoria externa tem por função avaliar a coerência dos achados, minimizando inferências do pesquisador (Hill, 2012). Na terceira etapa, a dupla que codificou a entrevista criou categorias unindo as ideias centrais sobre um mesmo tema e as enviou novamente para auditoria. Depois de concluída a análise de todas as entrevistas, verificou-se a frequência com que as categorias surgiram, classificando como "geral" as que apareceram em todas as entrevistas, "típica" as que apareceram em mais da metade e "variante" as que apareceram em uma ou duas entrevistas. 


\section{RESULTADOS E DISCUSSÃO}

A análise de conteúdo realizada gerou 29 categorias, organizadas em quatro domínios: identidade sexual, vínculo conjugal, processo da parentalidade e exercício da parentalidade. Na Tabela 2, estão representados os domínios, as categorias, a classificação das respostas e a síntese das respostas mais frequentes dadas pelos casais.
Identidade Sexual

Neste domínio, os participantes referiram que, apesar de terem vivenciado experiências heterossexuais, perceberam o desejo por pessoas do mesmo sexo na adolescência: " $E u$ vivia com as pessoas, namorava com pessoas" (César). A

Tabela 2

Domínios, categorias, classificação e sintese dos resultados

\begin{tabular}{|c|c|c|}
\hline $\begin{array}{l}\text { Domínios/ } \\
\text { Categorias }\end{array}$ & Classificação & Síntese dos resultados \\
\hline \multicolumn{3}{|l|}{ Identidade sexual } \\
\hline Descoberta & Geral & $\mathrm{Na}$ adolescência \\
\hline Assunção & Geral & Homossexualidade foi percebida pela convivência \\
\hline Apoio & Variante & De amigos \\
\hline Preconceito & Típica & De parentes próximos \\
\hline Relação social & Variante & Busca por amigos homossexuais \\
\hline \multicolumn{3}{|l|}{ Vínculo conjugal } \\
\hline Relacionamento & Geral & Rapidez ao assumir a relação \\
\hline Casamento & Variante & Garantir direitos de cônjuges e filhos \\
\hline Apoio & Típica & De amigos e familiares \\
\hline Preconceito & Variante & Receio social \\
\hline Relação social & Típica & Não expõe e nem esconde a relação \\
\hline \multicolumn{3}{|l|}{ Processo } \\
\hline Desejo & Geral & Somente um dos cônjuges queria a parentalidade \\
\hline Motivação & Geral & Vivências, idade, condições financeiras e psíquicas \\
\hline Método & Típico & Adoção \\
\hline Perfil & Típica & Até dois irmãos, de até 5 anos e sem doença incurável \\
\hline Processo & Geral & Lento enquanto estavam à espera da concretização, mas rápido após a efetivação \\
\hline Apoio & Típica & Assistentes sociais, clínica de fertilização e familiares \\
\hline Relações sociais & Variante & Não contaram sobre o processo da parentalidade \\
\hline Planejamento familiar & Típica & Realizado após a efetivação da parentalidade \\
\hline Dificuldades & Variante & Negativa ao tentar realizar a FIV em uma clínica católica \\
\hline \multicolumn{3}{|l|}{ Exercício } \\
\hline Adaptações & Geral & $\begin{array}{l}\text { Alterar locais que frequentavam e horários, realizar mais programas de lazer em casa e } \\
\text { mudança para residência maior }\end{array}$ \\
\hline Família biológica & Variante & $\begin{array}{l}\text { Filhos eram agredidos e/ou negligenciados e não mantêm contato com a família } \\
\text { biológica }\end{array}$ \\
\hline Relação com o filho & Geral & Afetiva com espaço para diálogo \\
\hline Papéis parentais & Geral & Alternância nos cuidados \\
\hline Filhos(as) e pessoas do sexo oposto & Típica & Proximidade com pessoas de ambos os sexos \\
\hline Apoio & Geral & De amigos, familiares, babá e creche/escola \\
\hline Preconceito & Típica & Não percebem situações de preconceito \\
\hline Relações sociais & Geral & Parentalidade leva a assumir a sexualidade e o relacionamento \\
\hline Direitos & Geral & Recursos jurídicos para garantir benefícios da parentalidade \\
\hline Educação & Variante & Criá-los com carinho e sem preconceito \\
\hline
\end{tabular}


exceção foi Denise que, até os 30 anos de idade, não havia se relacionado com mulheres e o surgimento desse desejo veio após um casamento heterossexual de 10 anos: "Um ano depois (da separação), eu já comecei a sair com mulheres... e o interessante é que eu me perguntava: 'Onde estava isso todos esses anos?",

Ao serem questionados sobre sua orientação sexual, todos os participantes demonstraram dificuldade em definir sua sexualidade e concluíram que o único fator que poderia determinar isso é a relação que vivem. A partir disso, é possível perceber que a necessidade de nomear a forma com que os sujeitos se relacionam é mais importante a nível social do que para o próprio sujeito que vive nessa relação.

Os homens revelaram que nunca declararam suas relações homossexuais para seus pais e mães e, inicialmente, apresentavam os namorados como amigos. Sendo assim, a percepção da sexualidade foi dada pela convivência, como retrata Bruno: "Eu nunca cheguei e disse (que era gay), as coisas foram acontecendo. Com o tempo, eles foram sacando. A primeira vez que a gente dormiu em uma cama de casal lá (na casa dos pais), foi a mãe que disse que ia arrumar o quarto que tem a cama de casal pra gente". No caso das mulheres, ambas contaram inicialmente para suas mães e depois para o restante da família.

Metade dos entrevistados relataram ter sofrido com a homofobia de seus familiares, tendo, em suas percepções, a religião como forte motivo para isso: "A primeira reação da minha mãe foi jogar todos meus santos fora" (Denise). No entanto, outros participantes receberam apoio, principalmente dos amigos.

A adolescência é um período marcado por intensas transformações físicas e psíquicas, tendo como uma das principais características o desenvolvimento da identidade sexual. A fala dos participantes corrobora o que demais pesquisas apontam sobre a adolescência ser o período das primeiras experiências homossexuais e, portanto, da percepção da sexualidade (Alves, Parente, \& Albuquerque, 2016; Rodrigues \& Carmo, 2013). Essa etapa de descobertas e modificações pode se tornar mais estressora que o habitual para minorias sexuais se, no momento em que compreenderem e vivenciarem sua sexualidade, não contarem com o apoio social.

De modo a amparar esses achados, estudos desenvolvidos que objetivaram avaliar o apoio da família na assunção da homossexualidade de adolescentes e jovens revelam que a rejeição familiar resulta em confusão de identidade e atitudes homofóbicas internalizadas (Nunan, 2010; Willoughby, Doty, \& Malik, 2010). A religião e a cultura do país também são fatores que influenciam e estimulam a homofobia (Hildebrandt, 2014), preconceito que é generalizado na sociedade brasileira (Costa, Peroni, Bandeira, \& Nardi, 2013). Reflexões acerca desse resultado sugerem que, apesar de diversas mobilizações sociais e de uma maior abertura para se pensar sobre as sexualidades, a descoberta e a revelação da identidade sexual ainda são dificultadas pelos padrões heternormativos sociais (Alves, Parente \& Albuquerque, 2016; Costa, Machado, \& Wagner, 2015), que podem resultar não só no afastamento familiar, mas em violências psíquicas imprimidas pelos pais (Soliva \& Junior, 2014).

\section{Vínculo Conjugal}

Os casais se conheceram em locais públicos e não levaram mais de 2 meses entre ter o primeiro encontro e morar junto. De acordo com Daniela, "lésbica não marca segundo encontro, marca mudança". A rapidez em assumir a relação, segundo as entrevistadas, está associada à dificuldade em expressar livremente seu afeto em ambientes públicos, limitando os locais que o casal frequenta: "É que só pode em certos lugares, para ficar à vontade, para dar beijo" (Denise); "Por isso a gente acaba se fechando em determinados lugares. E por isso também da escolha de ir morar junto tão rápido, fazer uma vida juntas tão rápido, para ter essa convivência mais intensa" (Daniela). Considerando que esses sujeitos vivem em condição de minoria sexual, expor a relação pode resultar em esgotamento emocional (Goldberg, Kinkler, Moyer, \& Weber, 2014), o que é evitado quando os casais optam por viver a relação dentro de casa.

$\mathrm{O}$ reconhecimento legal do casamento entre pessoas do mesmo sexo traz a sensação de segurança e proteção para esses pares (Shulman, Gotta, \& Green, 2012) e esses foram os fatores que levaram os casais B e D a realizarem o casamento civil: "Se nós fôssemos somente dois caras morando juntos, as famílias faziam e fazem isso de tomar o bem para elas (tomar o imóvel em caso de falecimento)" (Bernardo); "Essa questão do casamento até então não era necessária, porque a gente já era casada. Para mim, já era. Mas foi por conta dos filhos" (Denise).

Os casais B, C e D afirmaram receber apoio de conhecidos, amigos e familiares em seus relacionamentos, sendo que os casais B e D também vivenciaram situações de preconceito. Para eles, a sociedade percebe a relação entre homossexuais como erótica e perversa: "Se tu és um casal homossexual, basicamente prevalece a questão do sexo. Ninguém lembra que tens que pagar a conta de luz (...). As pessoas esquecem que tem o amor, o carinho" (Bernardo).

Daniela percebe diferenças entre o preconceito sofrido por gays e lésbicas. $\mathrm{Na}$ opinião dela, ver dois homens se beijando é ofensivo, enquanto ver duas mulheres é convidativo e provocador. E, de fato, esse dado é corroborado por pesquisas que mostram que, de modo geral, a sociedade demonstra maior tolerância com relacionamentos de lésbicas do que de gays (Paiva, Aranha, \& Bastos, 2008; Webb, Chonody, \& Kavanagh, 2016). Isso remete às expectativas características de uma sociedade machista em relação ao homem cisgênero e a sua masculinidade hegemônica, que determinam postura, fala e gestos a serem moldados por normas de conduta de uma lógica binária. Quando esse 
sujeito as extrapola, causa desconforto. Visto isso, estudos queer se tornam importantes na tentativa de ampliar a visão do masculino, pensando na pluralização das expressões corporais e de afeto (Andrêo, Peres, Tokuda, \& Souza, 2016). Bernardo entende que o estranhamento social é natural, mas o que deve prevalecer nas relações é o respeito e não a aceitação: "Eu acho que a gente nunca deixou que as pessoas passassem. Tem uma cerca e tu ficas do lado de lá se não gostou. Daqui pra cá, é meu".

Apenas um casal participa de grupos que defendem os direitos de homossexuais. Os demais dizem não ter interesse em expor a relação, como mostra Daniela: "Não levanto bandeira, mas também não me escondo. Nenhum heterossexual sai gritando pela rua dizendo 'Sou hétero, me respeitem'e eu também não preciso fazer isso".

Apoio e preconceito são categorias presentes em distintos momentos da vida conjugal dos participantes. Percebe-se que, com o avanço da relação, o apoio da família de origem tende a aumentar e o preconceito diminuir, corroborando achados de outros estudos (Bramlett, 2012; Merino, 2013; Rostosky et al., 2004).

\section{Processo da Parentalidade}

Em todos os casais, o desejo de ter filhos se manifestou inicialmente em um dos cônjuges e a busca pela parentalidade ocorreu ou por influência deste (casal C) ou quando o desejo surgiu no(a) outro(a) parceiro(a) (casais A, B e D). Pesquisas revelam que homossexuais são menos propensos a demonstrar desejo de parentalidade que heterossexuais (Baiocco, Argalia, \& Laghi, 2013; Riskind \& Patterson, 2010). Isso pode ser compreendido pelas dificuldades adicionais em alcançar a parentalidade, já que existe uma incapacidade biológica de reprodução (Murphy, 2013; Wall, 2013), bem como pelo receio da reação da sociedade e por sentimentos discriminatórios internalizados (Kleinert, Martin, Brähler, \& Stöbel-Richter, 2015).

Os fatores que motivaram a parentalidade foram as relações próximas com crianças e adolescentes - sobrinhos e afilhados afetivos1 (casais A e B) - e a busca por satisfação e completude pessoal (casal C). O momento ideal para ter filhos foi escolhido devido à idade do casal (casais $\mathrm{C}$ e D), estabilidade conjugal e financeira (casais B e D) e sensação de que tinham condições de criar e educar os filhos (casais A, B, C e D), fatores que fazem parte da progressão natural de qualquer relacionamento amoroso (Goldberg, Downing, \& Moyer, 2012; Kleinert et al., 2015). Em todos os casos, a possibilidade de efetivar a parentalidade surge como etapa importante após plena estruturação do casal, possibilitando que venham a se tornar uma família. Esses dados são corroborados por pesquisas realizadas com casais de classe

1 O Programa de Apadrinhamento Afetivo tem o objetivo de proporcionar uma vivência familiar para crianças e adolescentes abrigados que, pelo seu perfil, têm menores chances de adoção. Os padrinhos podem passear com o afilhado, acompanhar sua rotina escolar e levá-lo para passar um dia ou um fim de semana em sua residência. média, que mostram como o desejo à parentalidade surge após o casal ter atingido estabilidade profissional e financeira (Fonseca, 2006; Machin, 2016; Ramírez-Gálvez, 2011).

O método escolhido para alcançar a parentalidade foi a adoção nos casais de homens e a FIV no casal de mulheres. Os casais A e B decidiram, desde o primeiro momento, que a adoção era a única opção viável: "A gente sempre foi da opinião de que já tem tanta criança no mundo... $\mathrm{O}$ amor é o mesmo (André)". Bernardo, no entanto, recebeu uma proposta de um casal de amigas lésbicas para engravidar uma delas, mas recusou o convite pelo desejo de ter um filho na relação com seu companheiro. Antes da adoção, César cogitou engravidar uma amiga, mas a motivação para desistir do processo foi a mesma do casal B. Antes da adoção, o casal ainda tentou a "adoção à brasileira", quando a família biológica entrega a criança para um casal, desconsiderando os trâmites legais necessários. O objetivo de buscar esse meio era não ter que esperar na fila de adoção e concretizar a parentalidade de maneira imediata, mas sempre que conseguiam uma criança para adotar, alguém da família biológica se responsabilizava por ela e adoção não era concluída.

Existem diversas formas de alcançar a parentalidade e a análise da literatura revela que a escolha do método é diretamente influenciada pelo contexto social e legislações vigentes nos países em que os casais vivem. No Brasil, gays e lésbicas podem ter filhos através da adoção, de relações heterossexuais, de técnicas de reprodução assistida e em acordos coparentais. Para os participantes desta pesquisa, o desejo de ter filho(s) estava vinculado ao exercício conjunto da parentalidade, resultando, portanto, na adoção e na FIV como os métodos escolhidos.

$\mathrm{O}$ processo de adoção dos casais $\mathrm{A}, \mathrm{B}$ e $\mathrm{C}$ foi percebido como lento enquanto esperavam na fila, mas rápido após conhecerem a(s) criança(s). Os casais B e D tiveram que readequar, respectivamente, o perfil da criança adotada e do doador do sêmen. O casal D escolheu um pai biológico que desenvolvesse atividades de lazer e apresentasse características físicas parecidas com a mãe não biológica. Os casais A e B queriam adotar até dois irmãos, com, no máximo, 5 anos de idade e que não tivessem uma doença incurável. Além dessas características, o casal B preferia adotar meninos de cor branca, mas mudou o perfil quando percebeu que isso implicaria mais tempo para concretizar a adoção.

Pais e mães tendem a escolher perfis de sêmen e de filhos adotivos que apresentem características físicas semelhantes a, pelo menos, um dos cônjuges, visando reduzir as diferenças (Ryan \& Berkowitz, 2009). Não obstante, essa readequação do perfil da criança tende a ser aceita mais facilmente por gays, que hierarquicamente podem se sentir inferiorizados e impelidos a aceitar essas mudanças (Golding, 2006).

Os participantes receberam apoio dos assistentes sociais (casal A), da equipe da clínica de FIV (casal D) e de pais, mães e primos (casal C): "Uma coisa que veio junto foi a força da minha mãe, o apoio dela" (César). O casal D 
relatou dificuldades no processo ao tentar realizar a FIV em uma clínica católica que se recusou a fazê-la, pois, embora se garanta o acesso às técnicas de reprodução assistida, ao médico também é garantido o direito de objeção de consciência.

Os casais A e B preferiram não contar sobre o desejo e o processo da parentalidade para os familiares. O casal $\mathrm{C}$ foi o único que desenvolveu um planejamento familiar antes da efetivação da adoção e definiu que adotariam os três irmãos ou nenhum. O casal B tem planos de adotar o irmão biológico dos meninos, caso ele seja abrigado e o casal D pensa na possibilidade de adoção ou outras FIV.

\section{Exercício da Parentalidade}

Os casais relataram adaptações e mudanças necessárias na vida conjugal para viver a parentalidade. As mudanças mais comuns foram adequar os locais que frequentavam $\mathrm{e}$ horários para que os filhos os acompanhassem (casais A, B e C), reduzir os programas fora de casa (casais A e B), mudar de residência para um local com mais espaço (casais C e D), contratar babá (casal B) e sair do emprego para ter mais tempo com os filhos (Carlos).

Na relação com os filhos, os pais e mães são afetivos (casais A, B, C e D) e possibilitam espaço para diálogo (casais B e C). Os entrevistados relatam que pais, mães e filhos se sentem felizes e adaptados com a rotina. Na família do casal B, por exemplo, foi estabelecido o dia da família, em que todos os integrantes desenvolvem alguma atividade juntos. Em relação à homossexualidade dos pais, o filho mais velho do casal $\mathrm{C}$ demonstrou estranhamento logo após a adoção, que foi solucionado por meio de conversas e da aproximação de amigos com diferentes configurações familiares. Outra dificuldade nas relações é o medo que os filhos têm de serem devolvidos para o abrigo (filhos dos casais B e C), reeditando o trauma do abandono. Percebe-se que a parentalidade gerou diversas mudanças para os casais e seus filhos, que inicialmente foram sentidas como difíceis, mas com o passar do tempo foram superadas. Quando a parentalidade é vivida de maneira positiva, os filhos sentemse adaptados com a sexualidade dos pais (Fairthlough, 2008), o que parece ocorrer nos casos analisados.

Nos casais A, B e D, os papéis desempenhados nos cuidados com os filhos se alternam entre os pais e as mães, como pode ser constatado na fala de André: "Quando o Alex chega, dá banho nele, eu visto, ele janta e vai dormir. Nada assim predeterminado. Se eu não consigo fazer hoje o Alex faz amanhã de manhã". No casal C, Carlos assume a educação dos filhos e César mantém financeiramente a casa. A flexibilidade nos papéis parentais é comum em casais do mesmo sexo (Farr \& Patterson, 2013; Rodriguez \& Paiva, 2009), que compartilham melhor os cuidados na casa e na educação das crianças, do que casais heterossexuais (Goldberg, Smith, \& Perry-Jenkins, 2012).
Em relação à maneira como a família se relaciona na sociedade, todos os casais concordam que a parentalidade é a efetivação da homossexualidade e do compromisso com o cônjuge: "Não que eles (conhecidos) não soubessem, mas se alguém algum dia ficou com dúvida, a história do nosso filho trouxe tudo à tona" (Alex); "Nós tivemos que deixar de lado nossos próprios preconceitos, nos assumir como casal, nossos filhos, nossa estrutura familiar" (César).

Os casais A, B e C não percebem situações de preconceito por serem famílias formadas por pais gays. De acordo com os participantes, isso acontece porque o mundo está mudando e aceitando aos poucos diferentes configurações familiares (casal B) e porque o preconceito diminui quando são vistos como uma família e não um casal (casal D): “( $A$ maternidade) tirou esse ar de promiscuidade, ficou só uma familia. 'Olha que bonito, elas têm dois filhos"' (Denise); "A mãe dos colegas de judô dos guris sempre olhava para nós. Eu achava que ela era um pouco antipática, mas um dia ela disse que sempre quis falar conosco para elogiar nosso ato" (de adoção) (Bruno); "Levamos a vida como se fôssemos uma família dita tradicional" (Carlos). Embora já estivessem em relacionamentos duradouros e estáveis, foi a parentalidade que resultou na inclusão social desses casais. Isso é percebido pela mudança na resposta da sociedade quando eles se tornaram pais e mães.

Os casais B, C e D não deixam de desempenhar atividades que consideram importantes por medo do preconceito, por exemplo, ter uma participação ativa na escola dos filhos. O casal B destaca que a maioria das pessoas convive naturalmente com a família; porém, em uma ocasião, um colega dos filhos foi afastado do convívio com eles após seu pai ter descoberto que Bruno e Bernardo eram um casal. Apesar de afirmarem que não vivenciaram situações de preconceito, a maioria dos amigos do casal C não reagiu como o esperado após a decisão da parentalidade, pois acreditavam que o casal não iria se adaptar ao estilo de vida de uma família com filhos.

Todos os entrevistados receberam apoio no momento da parentalidade e relataram que hoje em dia a família extensa lida bem com a homossexualidade. $\mathrm{O}$ apoio foi recebido dos amigos (casais A, B e D), familiares (casais C e D), babá (casais B e C), creche e escola (casais A e D), vizinha (casal A) e colegas de trabalho (casal D). As pesquisas sugerem que, para a grande maioria dos pais e mães, a parentalidade os aproximou da família de origem, mesmo quando a primeira reação foi negativa (Palma \& Levandowski, 2008; Power et al., 2012). Além disso, o desejo dos avós de vivenciar essa nova relação fez com que o preconceito com a sexualidade do filho diminuísse (Power et al., 2012). Pais que receberam apoio no ambiente de trabalho relatam menos sintomas depressivos e ansiosos (Goldberg \& Smith, 2013). Em todos os casais entrevistados, ficou evidente a importância do suporte recebido, bem como a satisfação com o exercício da parentalidade. $\mathrm{O}$ apoio social parece ser 
essencial para que tornar-se pai ou mãe seja fonte de prazer e satisfação mais do que de sofrimento e ansiedade.

A maioria dos participantes teve que contar com o auxílio jurídico para garantir os direitos no exercício da parentalidade. Os casais A e B entraram com um recurso para conseguir a licença paternidade e o casal D está com um processo em andamento para que o nome das duas mães conste na certidão de nascimento dos filhos. Em situações em que foi necessário o preenchimento de dados parentais das crianças, os casais B, C e D requisitaram que fosse efetuada a troca de "mãe e pai" para "mãe e mãe" ou "pai e pai":

O mais novo esses tempos ficou doente e eu levei no hospital. Ele passou primeiro com um técnico de enfermagem que pediu "Nome da mãe? Nome do pai?" Eu disse o nome do pai e ele perguntou de novo o nome da mãe. Eu falei "Ele não tem mãe”, e o técnico “Como não tem mãe?”, eu pedi para ele se acalmar e repeti que ele não tinha mãe. Meu filho me olhou, ele estava no meu colo e falou "Eu não tenho mãe, tenho dois papais". (Carlos)

Ter duas mães ou dois pais não significa privar a criança do convívio com adultos de um ou outro sexo. Uma pesquisa realizada com mães lésbicas revelou que as entrevistadas consideram importante o contato dos seus filhos(as) com pessoas do sexo masculino (Goldberg \& Allen, 2007). Nesse sentido, os casais A, B e D destacaram a importância da proximidade dos filhos com pessoas do sexo oposto ao deles, especialmente com madrinhas (casais A e B), padrinhos (casal D), tias (casal A), avós (casais A e B) e avôs (casal D).

Os casais B e C conhecem a história da família biológica de seus filhos e contam que, em ambos os casos, os filhos mais velhos foram agredidos e os mais novos negligenciados. Os filhos do casal B eram da mesma mãe, mas de pais diferentes e os filhos do casal $\mathrm{C}$ eram de pais biológicos desconhecidos. Os filhos do casal $\mathrm{C}$ têm diversos irmãos por parte de mãe e quem cuidava deles era uma das irmãs, na época com 7 anos, que hoje está abrigada. Os filhos pedem para se relacionar com as irmãs, mas os pais ficam em dúvida se isso é positivo para as crianças:
Deixávamos eles conviverem, só agora que não porque elas estão em um abrigo. Acho também que seria uma afronta contra elas. Imagina elas chegarem em uma casa gigantesca, os irmãos delas super bem, em uma família super estruturada e elas nada, acho que seria um choque muito grande (...) Quando a gente encontrava as outras irmãs na pracinha, nossa filha simplesmente parava de falar e fazia xixi na cama três, quatro dias seguidos. Fazia muito mal aquele encontro para ela, estranho, mas fazia. (Carlos)

Atualmente, os filhos dos casais $\mathrm{B}$ e $\mathrm{C}$ não mantêm contato com a família biológica.

Na educação dos filhos, os entrevistados priorizam criálos com carinho (casal B), sem preconceitos (casais B e D) e com liberdade para fazerem suas próprias escolhas (casal D). As entrevistas revelam que esses casais desejam que seus filhos cresçam capazes de enfrentar as adversidades da vida sem muito sofrimento. Possivelmente, essa preocupação tenha raiz nas situações de preconceito que eles próprios sofreram, direta ou indiretamente. Para eles, o afeto aliado à aceitação das diferenças é fundamental para que os filhos cresçam saudáveis e capazes de se defender, como enfatizou Daniela: "A nossa ideia é ensiná-los a naturalidade desse tipo de relação e qualquer tipo de relação, para que eles consigam se defender se for preciso".

Sabe-se que a adaptação de um indivíduo não depende da sexualidade dos pais (Gartrell \& Bos, 2010; Oliva, Arranz, Parra, \& Olabarrieta, 2014; Wainright, Russell, \& Patterson, 2004), mas sim de um ambiente favorável, amoroso, estimulante e livre de conflitos (Oliva et al., 2014). $O$ presente estudo não se concentrou na experiência de filhos de casais homossexuais e sim na de seus pais. Entretanto, o discurso dos entrevistados permite pressupor que seus filhos sejam mais propensos à empatia e à solidariedade, uma vez que sua educação familiar enfatiza, de forma muito clara, direta e transparente, que todos devem ser respeitados pelo que são, como relata Bruno: "Nós não podemos ser preconceituosos, porque a gente tem uma carrada de motivos para que os outros sejam preconceituosos, então porque que nós vamos fazer a mesma coisa que os outros fazem?"

\section{CONSIDERAÇÕES FINAIS}

Os achados revelam que esses casais vivenciam a parentalidade de maneira positiva, estabelecendo vínculos saudáveis e de confiança entre pais e filhos ou mães e filhos. Porém, por viverem em uma sociedade heteronormativa, a parentalidade de casais do mesmo sexo traz consigo uma carga de medos e desafios inerente aos sujeitos desde o momento da descoberta da sua sexualidade.

O receio de passar por situações de preconceito fez com que os casais assumissem com rapidez seus relacionamentos para vivê-los dentro de casa ou em ambientes privados que respeitam sua sexualidade e evitam a exposição social. No entanto, analisando a história dos casais desde a descoberta e a assunção da homossexualidade até o desejo e a efetivação da parentalidade, percebe-se a uma diminuição do preconceito, especialmente da família de origem, e um aumento do apoio social.

A exposição da relação se torna impreterível quando os casais efetivam o desejo de se tornarem pais e mães. A conjugalidade e a parentalidade parecem desempenhar um importante papel na superação de comportamentos evitativos, fazendo com que os casais se sintam mais confiantes e seguros nas interações sociais. Considerando os valores que 
priorizam na educação dos seus filhos, pode-se dizer que a parentalidade homossexual, nesses casos, traz consigo o desejo de que a próxima geração seja mais livre para fazer escolhas e mais tolerante às diferenças do que a atual.

Este foi um estudo qualitativo, com um número reduzido de participantes, de elevado nível de escolaridade, que foram selecionados por conveniência. Qualquer generalização dos achados para outros casos deve ser feita com cautela, já que a maior parte do referencial das pesquisas ainda é estrangeiro, sendo necessários outros estudos com essa população para que se possa estabelecer com mais segurança o que é comum à parentalidade homossexual brasileira.

Não se pode desconsiderar possível influência da desejabilidade social no conteúdo das entrevistas realizadas, nem relevar a possibilidade de que os participantes representem uma parcela mais adaptada e saudável da população, uma vez que casais disfuncionais, em conflito com a parentalidade e/ou com maior medo de exposição social provavelmente não aceitariam participar desse tipo de estudo. Não obstante, a maior parte das categorias foram classificadas típicas ou gerais, o que sugere a replicabilidade em outros casos. Além disso, constata-se que outras pesquisas corroboram alguns dos mais importantes achados deste estudo: a parentalidade em casais do mesmo sexo é exercida com satisfação e responsabilidade, revela a maturidade do casal, é facilitada pelo apoio e complicada pelo preconceito social, é caracterizada por flexibilidade nos papéis parentais; é preocupada com a transmissão de valores de igualdade e liberdade.

\section{REFERÊNCIAS}

Alves. M. J. H., Parente, J. S., \& Albuquerque, G. A. (2016). Homosexual orientation in childhood and adolescence: experiences of concealment and prejudice. Reprodução $e$ Climatério, 31(2), 68-75. doi: 10.1016/j.recli.2016.03.002

Andrêo, C., Peres, W. S., Tokuda, A. M. P., \& Souza, L. L. (2016). Homofobia na construção das masculinidades hegemônicas: Queerizando as hierarquias entre gêneros. Estudos e Pesquisas em Psicologia, 16(1), 46-67.

Baiocco, R., Argalia, M., \& Laghi, F. (2013). The desire to marry and attitudes toward same-sex family legalization in a sample of Italian lesbians and gay men. Journal of Family Issues, 35(2), 181-200. doi:10.1177/0192513X12464872

Bramlett, B. H. (2012). The cross-pressures of religion and contact with gays and lesbians, and their impact on same-sex marriage opinion. Politics \& Policy, 40(1), 13-30. doi:10.1111/j.17471346.2011.00337.x

Corrêa, M. E. C. (2012). Duas mães? Mulheres lésbicas e maternidade (Tese de Doutorado). Faculdade de Saúde Pública, Universidade de São Paulo, São Paulo, SP, Brasil. doi:10.11606/T.6.2012.tde-29042012-124625

Costa, A. B., Peroni, R. O., Bandeira, D. R., \& Nardi, H. C. (2013). Homophobia or sexism? A systematic review of prejudice against nonheterosexual orientation in Brazil. International Journal of Psychology, 48(5), 900-909. doi:10.1080/002075 94.2012.729839

Costa, C. B., Machado, M. R., \& Wagner, M. F. (2015). Percepções do homossexual masculino: Sociedade, família e amizades. Temas em Psicologia, 23(3), 777-788. doi: 10.9788/TP2015.320

D’Augelli, A. R., Rendina, J., \& Sinclair, K. O. (2007). Gay and lesbian youth want long-term couple relationships and raising children. Journal of LGBT Issues in Counseling, 1(4), 77-98. doi:10.1177/0192513X13484272

Fairthlough, A. (2008). Growing up with a lesbian or gay parent: Young people's perspectives. Health and Social Care in the Community, 16(5), 521-528. doi:10.1111/j.13652524.2008.00774.x

Farr, R., \& Patterson, C. J. (2013). Coparenting among lesbian, gay, and heterosexual couples: Associations with adopted children's outcomes. Child Development, 84(4), 1226-1240. doi:10.1111/cdev.12046

Fonseca, C. (2006). Da circulação de crianças à adoção internacional: Questões de pertencimento e posse. Cadernos Pagu, 26, 11-43. doi: 10.1590/S0104-83332006000100002
Gartrell, N., \& Bos, H. (2010). US national longitudinal lesbian family study: Psychological adjustment of 17-year-old adolescents. Pediatrics, 126(3), 28-36. doi:10.1542/peds.20093153

Gates, G., Badgett, L. M., Macomber, J. E., \& Chambers, K. (2007). Adoption and foster care by lesbian and gay parents in the United States. Washington, DC: The Urban Institute and The Williams Institute.

Goldberg, A. E. (2010). Lesbian and gay parents and their children: Research on the family life cycle. Washington, DC: American Psychological Association.

Goldberg, A. E., \& Allen, K. R. (2007). Imagining men: Lesbian mother's perceptions of male involvement during the transition to parenthood. Journal of Marriage and Family, 69(2), 352365. doi:10.1111/j.1741-3737.2007.00370.x

Goldberg, A. E., \& Smith, J. Z. (2013). Work conditions and mental health in lesbian and gay dual-earner parents. Family Relations, 62(5), 727-740. doi:10.1111/fare. 12042

Goldberg, A. E., Downing, J. B., \& Moyer, A. M. (2012). Why parenthood, and why now? Gay men's motivations for pursuing parenthood. Family Relations, 6(1), 157-174. doi:10.1111/ j.1741-3729.2011.00687.x

Goldberg, A. E., Kinkler, L. A., Moyer, A. M., \& Weber, E. B. (2014). Intimate relationship challenges in early parenthood among lesbian, gay, and heterosexual couples adopting via the Child Welfare System. Professional Psychology: Research and Practice, 45(4), 221-230. doi:10.1037/a0037443

Goldberg, A. E., Smith, J. Z., \& Perry-Jenkins, M. (2012). The division of labor in lesbian, gay, and heterosexual new adoptive parents. Journal of Marriage and Family, 74(4), 812-828. doi:10.1111/fare. 12042

Golding, A. C. (2006). Redefining the nuclear family: An exploration of resiliency in lesbian parents. Journal of Feminist Family Therapy, 18(1/2), 35-65. doi:10.1300/J086v18n01 02

Golombok, S., Mellish, L., Jennings, S., Casey, P., Tasker, F., \& Lamb. M. E. (2014). Adoptive gay father families: Parent-child relationships and children's psychological adjustment. Child Development, 85(2), 456-68. doi: 10.1111/cdev.12155

Hildebrandt, A. (2014). Routes to decriminalization: A comparative analysis of the legalization of same-sex sexual acts. Sexualities, 17(1/2), 230-253. doi:10.1177/1363460713511105

Hill, C. E. (2012). Consensual Qualitative Research: A practical resource for investigating social science phenomena. Washington, DC: American Psychological Association. 
Kleinert, E., Martin, O., Brähler, E., \& Stöbel-Richter, Y. (2015). Motives and decisions for and against having children among nonheterosexuals and the impact of experiences of discrimination, internalized stigma, and social acceptance. Journal of Sex Research, 52(2), 174-185. doi:10.1080/002 24499.2013.838745

Machin, R. (2016). Homoparentalidade e adoção: (Re)afirmando seu lugar como família. Psicologia \& Sociedade, 28(2), 350359. doi: 10.1590/1807-03102016v28n2p350

Meletti, A. T., \& Scorsolini-Comin, F. (2015). Conjugalidade e expectativas em relação à parentalidade em casais homossexuais. Psicologia: Teoria e Prática, 17(1), 37-49. doi: $10.15348 / 1980-6906$

Merino, S. M. (2013). Contact with gays and lesbians and samesex marriage support: The moderating role of social context. Social Science Research, 42(4), 1156-1166. doi:10.1016/j. ssresearch.2013.02.004

Miscioscia, M., Blavier, A., Pagone, P. R., \& Simonelli, A. (2017) The desire of parenthood: Intuitive co-parental behaviors and quality of couple relationship among Italian and Belgian same-sex and opposite-sex couples. Frontiers in Psychology, 110(8), 1-9. doi: 10.3389/fpsyg.2017.00110

Murphy, D. A. (2013). The desire for parenthood gay men choosing to become parents through surrogacy. Journal of Family Issues, 34(8), 1104-1124. doi:10.1177/0192513X13484272

Nunan, A. (2010). Preconceito internalizado e comportamento sexual de risco em homossexuais masculinos. Psicologia Argumento, 28(62), 247- 259.

Oliva, A., Arranz, E., Parra, A., \& Olabarrieta, F. (2014). Family structure and child adjustment in Spain. Journal of Child \& Family Studies, 23(1), 10-19. doi:10.1007/s10826-0129681-2

Paiva, V., Aranha, F., \& Bastos, F. (2008). Opiniões e atitudes em relação à sexualidade: Pesquisa de âmbito nacional, Brasil 2005. Revista de Saúde Pública, 42(1), 54-64. doi:10.1590/ S0034-89102008000800008

Palma, Y. A., \& Levandowski, D. C. (2008). Vivências pessoais e familiares de homossexuais femininas. Psicologia em Estudo, 13(4), 771-779.

Pereira, C. R., Torres, A. R. R., Falcão, L., \& Pereira, A. S. (2013). O papel de representações sociais sobre a natureza da homossexualidade na oposição ao casamento civil e à adoção por famílias homoafetivas. Psicologia: Teoria e Pesquisa, 29(1), 79-89. doi:10.1590/S0102-37722013000100010

Power, J., Perlesz, A., McNair, R., Schofield, M., Pitts, M., Brown, R., \& Bickerdike, A. (2012). Gay and bisexual dads and diversity: Fathers in the Work, Love, Play study. Journal of Family Studies, 18(2-3), 143-154. doi:10.5172/ jfs.2012.18.2-3.143
Ramírez-Gálvez, M. (2011). Inscrito nos genes ou escrito nas estrelas? Adoção de crianças e uso de reprodução assistida. Revista de Antropologia, 54(1), 47-87.

Riskind, R. G., \& Patterson, C. J. (2010). Parenting intention and desires among childless lesbian, gay and heterosexual individuals. Journal of Family Psychology, 24(1), 78-81. doi:10.1037/a0017941

Rodrigues, M. A., \& Carmo, M. (2013). A configuração do significado de família para homossexuais: Um estudo fenomenológico. Revista da Abordagem Gestáltica, 19(1), 12-20.

Rodriguez, B., \& Paiva, M. L. (2009). Um estudo sobre o exercício da parentalidade em contexto homoparental. Vinculo, 6(1), 13-25.

Rostosky, S. S., Korfhage, B. A., Duhigg, J. M., Stern, A. J., Bennett, L., \& Riggle, E. D. B. (2004). Same-sex couple perceptions of family support: A Consensual Qualitative study. Family Process, 43(1), 43-57. doi:10.1111/j.15455300.2004.04301005.x

Ryan, M., \& Berkowitz, D. (2009). Constructing gay and lesbian parent families "beyond the closet". Qualitative Sociology, 32(2), 153-172. doi:10.1007/s11133-009-9124-6

Shenkman, G. (2012). The gap between fatherhood and couplehood desires among Israeli gay men and estimations of their likelihood. Journal of Family Psychology, 25(5), 828-832. doi:10.1037/a0029471

Shulman, J. L., Gotta, G., \& Green, R-J. (2012). Will marriage matter? Effects of marriage anticipated by same-sex couples. Journal of Family Issues, 33(2), 158-181. doi:10.1177/0192513X11406228

Soliva, T. B., \& Junior, J. B. S. (2014). Entre revelar e esconder: Pais e filhos em face da descoberta da homossexualidade. Sexualidad, Salud y Sociedad, 17, 124-148. doi: 10.1590/19846487.sess.2014.17.08.a

Wainright, J. L., Russell, S. T., \& Patterson, C. J. (2004). Psychosocial adjustment, school outcomes, and romantic relationships of adolescents with same-sex parents. Child Development, 75(6), 1886-1898.

Wall, M. L. (2013). Lesbians' perceived readiness to parent. Affilia: Journal of Women and Social Work, 28(4), 391-400. doi:10.1177/0886109913504723

Webb, S. N., Chonody, J. M., \& Kavanagh, P. S. (2016). Attitudes toward same-sex parenting: An effect of gender. Journal of Homosexuality, 64(11), 1583-1595. doi: 10.1080/00918369.2016.1247540

Willoughby, B. B., Doty, N. D., \& Malik, N. M. (2010). Victimization, family rejection, and outcomes of gay, lesbian, and bisexual young people: The role of negative GLB identity. Journal of GLBT Family Studies, 6(4), 403-424. doi:10.1080 /1550428X.2010.511085 